\title{
The influence of suspended particles on the mass transfer at a rotating disk electrode. Non-conducting particles
}

Citation for published version (APA):

Sonneveld, P. J., Visscher, W., \& Barendrecht, E. (1990). The influence of suspended particles on the mass transfer at a rotating disk electrode. Non-conducting particles. Journal of Applied Electrochemistry, 20(4), 563574. https://doi.org/10.1007/BF01008865

DOI:

10.1007/BF01008865

Document status and date:

Published: 01/01/1990

\section{Document Version:}

Publisher's PDF, also known as Version of Record (includes final page, issue and volume numbers)

\section{Please check the document version of this publication:}

- A submitted manuscript is the version of the article upon submission and before peer-review. There can be important differences between the submitted version and the official published version of record. People interested in the research are advised to contact the author for the final version of the publication, or visit the $\mathrm{DOI}$ to the publisher's website.

- The final author version and the galley proof are versions of the publication after peer review.

- The final published version features the final layout of the paper including the volume, issue and page numbers.

Link to publication

\section{General rights}

Copyright and moral rights for the publications made accessible in the public portal are retained by the authors and/or other copyright owners and it is a condition of accessing publications that users recognise and abide by the legal requirements associated with these rights.

- Users may download and print one copy of any publication from the public portal for the purpose of private study or research.

- You may not further distribute the material or use it for any profit-making activity or commercial gain

- You may freely distribute the URL identifying the publication in the public portal.

If the publication is distributed under the terms of Article 25fa of the Dutch Copyright Act, indicated by the "Taverne" license above, please follow below link for the End User Agreement:

www.tue.nl/taverne

Take down policy

If you believe that this document breaches copyright please contact us at:

openaccess@tue.nl

providing details and we will investigate your claim. 


\title{
The influence of suspended particles on the mass transfer at a rotating disc electrode. Non-conducting particles
}

\author{
P. J. SONNEVELD, W. VISSCHER, E. BARENDRECHT \\ Laboratory for Inorganic Chemistry and Catalysis, Eindhoven University of Technology, PO Box 513, \\ $5600 \mathrm{MB}$ Eindhoven, The Netherlands
}

Received 30 August 1989

The influence of suspended $\mathrm{SiC}$ particles on the mass transfer at an RDE (rotating-disc electrode) was investigated for the reduction of $\mathrm{K}_{3} \mathrm{Fe}(\mathrm{CN})_{6}$ and $\mathrm{ZnO}$ in alkaline electrolyte. A model for the increased mass transfer is developed, based on the decrease of the diffusion layer thickness by rotation of the particles in this layer. In experiments with different volume fractions of suspensions a critical value in the rotation speed and in volume fraction is found. The influences of hydrodynamic conditions, gravity, particle size and adhesion between particles and electrode were studied to investigate the origin of both critical values.

\begin{tabular}{|c|c|c|c|}
\hline \multicolumn{2}{|c|}{ Nomenclature } & \multirow{2}{*}{$\begin{array}{l}\dot{\gamma} \\
\Delta \delta \\
\delta_{\mathrm{N}}\end{array}$} & \multirow{2}{*}{$\begin{array}{l}\text { shear rate (at a RDE) }\left(\mathrm{s}^{-1}\right) \\
\text { decrease of the diffusion layer thickness }(\mathrm{m}) \\
\text { diffusion layer thickness (m) }\end{array}$} \\
\hline$A$ & area $\left(\mathrm{m}^{2}\right)$ & & \\
\hline$A_{132}$ & $\begin{array}{l}\text { Hamaker constant with liquid } 3 \text { between } \\
\text { materials } 1 \text { and } 2(\mathrm{Nm})\end{array}$ & $\delta_{\mathrm{P}}$ & $\begin{array}{l}\text { viscous boundary layer thickness }(\mathrm{m}) \\
\text { dynamic viscosity }(\mathrm{Pas})\end{array}$ \\
\hline$a$ & particle radius $(\mathrm{m})$ & $\psi$ & angle between $x_{1}$ axis and $\mathrm{r}(\mathrm{rad})$ \\
\hline$B$ & function defined in Equation $20\left(\mathrm{As}^{1 / 2} \mathrm{rad}^{-1 / 2}\right)$ & $v$ & kinematic viscosity $\left(\mathrm{m}^{2} \mathrm{~s}^{-1}\right)$ \\
\hline $\begin{array}{l}c \\
D\end{array}$ & $\begin{array}{l}\text { concentration of the reactants }\left(\mathrm{mol} \mathrm{m}^{-3}\right) \\
\text { diffusion coefficient }\left(\mathrm{m}^{2} \mathrm{~s}^{-1}\right)\end{array}$ & $\xi$ & $\begin{array}{l}\text { dimensionless distance in } z \text {-direction to a } \\
\mathrm{RDE}\end{array}$ \\
\hline$d$ & local decrease of the diffusion layer thickness & $\rho$ & density $\left(\mathrm{kg} \mathrm{m}^{-3}\right)$ \\
\hline $\bar{d}$ & $\begin{array}{l}\text { at a particle position }(\mathrm{m}) \\
\text { average decrease of the diffusion layer thick- }\end{array}$ & $\Delta \rho$ & $\begin{array}{l}\text { density difference between particle and liquid } \\
\left(\mathrm{kg} \mathrm{m}^{-3}\right)\end{array}$ \\
\hline & ness at a particle position $(\mathrm{m})$ & $\omega$ & angular velocity of a particle $\left(\mathrm{rad} \mathrm{s}^{-1}\right)$ \\
\hline$e$ & shear rate component $\left(\mathrm{s}^{-1}\right)$ & $\omega_{0}$ & angular velocity is shear flow $\left(\mathrm{rad} \mathrm{s}^{-1}\right)$ \\
\hline$F$ & force on a particle $(\mathrm{N})$ & $\dot{\omega}$ & angular acceleration of a particle $\left(\mathrm{rad} \mathrm{s}^{-2}\right)$ \\
\hline$g$ & gravitational constant $\left(\mathrm{m} \mathrm{s}^{-2}\right)$ & $\Omega$ & angular velocity of a $\operatorname{RDE}\left(\mathrm{rad} \mathrm{s}^{-1}\right)$ \\
\hline$h$ & distance between two particles $(\mathrm{m})$ & $\phi$ & volume fraction ( $\operatorname{vol} \%)$ \\
\hline $\begin{array}{l}H \\
I\end{array}$ & $\begin{array}{l}\text { dimensionless velocity in the } z \text {-direction } \\
\text { current (A) }\end{array}$ & $\varepsilon$ & bed expansion $($ vol $\%)$ \\
\hline$k$ & time constant $\left(\mathrm{s}^{-1}\right)$ & Sup & rscript \\
\hline K & $\begin{array}{l}\text { correction factor on the Stokes force for con- } \\
\text { centrated suspensions }\end{array}$ & $\mathrm{s}$ & $\begin{array}{l}\text { bulk solution } \\
\text { surface }\end{array}$ \\
\hline$M$ & total mass of all particles $(\mathrm{g})$ & & \\
\hline$M_{\mathrm{p}}$ & mass of one particle $(\mathrm{g})$ & $S u b$ & cript \\
\hline$n$ & number of electrons & a & adhesion \\
\hline$N$ & number of particles & $\mathrm{c}$ & critical value, centre \\
\hline$P$ & pressure $(\mathrm{Pa})$ & $\mathrm{E}$ & electrode \\
\hline$r_{0}$ & $\begin{array}{l}\text { radius of domain with active film transport } \\
\text { (m) }\end{array}$ & $\begin{array}{l}\mathrm{g} \\
i\end{array}$ & $\begin{array}{l}\text { gravitation } \\
\text { dimension index }\end{array}$ \\
\hline$r_{\mathrm{E}}$ & electrode radius (m) & $j$ & dimension index \\
\hline$r_{1}$ & $\begin{array}{l}\text { radius from the centre of a particle in the } x_{1} \\
-x_{2} \text { plane }(\mathrm{m})\end{array}$ & $\begin{array}{l}k \\
1\end{array}$ & $\begin{array}{l}\text { dimension index } \\
\text { diffusion limited }\end{array}$ \\
\hline$t$ & time $(\mathrm{s})$ & $\mathrm{N}$ & Nernst \\
\hline$u$ & velocity disturbance $\left(\mathrm{m} \mathrm{s}^{-1}\right)$ & o & outer \\
\hline$v$ & velocity $\left(\mathrm{m} \mathrm{s}^{-1}\right)$ & $\mathrm{p}$ & particle \\
\hline$x$ & coordinate & $\mathrm{P}$ & Prandtl \\
\hline$z$ & (axial) coordinate, distance in $z$-direction (m) & $\mathrm{R}$ & radial \\
\hline$z_{0}$ & $\begin{array}{l}\text { minimal approach distance between particles } \\
\text { and RDE }(\mathrm{m})\end{array}$ & $\begin{array}{l}\mathrm{r} \\
\mathrm{S}\end{array}$ & $\begin{array}{l}\text { radial direction } \\
\text { Stokes }\end{array}$ \\
\hline
\end{tabular}




\section{Introduction}

The rate of mass transfer of an electrode process can be enhanced via increased convection of the electrolyte, or by introducing turbulence promoters [1], gas bubbles [2,3], and solid particles [4-20]. The influence of glass spheres was measured by Leitel et al. [4] and Roha [5] for a RDE (rotating disc electrode) and by Smith et al. [6] for an electrode in a tube wall. Roha [5] also studied the influence of the particle size and found a weak maximum in the mass transfer when the particle diameter equals the diffusion layer thickness. Studies with sand particles in tubes were carried out by Postlethwaith et al. [7, 8] and Heitz [9]. Zeilmaker et al. [10] studied the influence of $\mathrm{CaCO}_{3}$ particles with an RDE electrode; Pini et al. [11] the addition of $\mathrm{SiC}$ at a rotating-cylinder electrode. Keller [12], Antonini et al. [13, 14] and Hyman [15] investigated a suspension of red blood cells in laminar flow cells (tubes). Caprani and co-workers [16-18] investigated the influence of suspensions of $\mathrm{SiC}, \mathrm{Al}_{2} \mathrm{O}_{3}, \mathrm{~B}_{4} \mathrm{C}$ and red blood cells with a rotating-disc electrode, and gave a theoretical model [19]. $\mathrm{Al}_{2} \mathrm{O}_{3}$ suspensions were studied in a Couette cell by Deslouis et al. [20]. All investigations show a remarkable increase in mass transfer, in some cases up to $300 \%$. It can easily be shown that the addition of particles cannot promote turbulence: the Reynolds number at an RDE with radius $\left(r_{\mathrm{E}}\right)$ is

$$
\operatorname{Re}_{\mathrm{E}}=2 \Omega r_{\mathrm{E}}^{2} / v
$$

with $\Omega=$ angular velocity of the electrode; $\Omega=2 \pi f$; $v=$ kinematic viscosity. For $R=5 \mathrm{~mm}$ and rotation frequency $f=64 \mathrm{rps}$ it follows that $\operatorname{Re}_{\mathrm{E}}=25400$. For $\mathrm{Re}_{E}<10^{5}$ the flow at the $\mathrm{RDE}$ is laminar [21]. Addition of particles with diameter 1 to $50 \mu \mathrm{m}$ increases the viscosity of the electrolyte and hence decreases $\mathrm{Re}_{\mathrm{E}}$, so that turbulence will not occur.

The hydrodynamic flow around a particle with radius $a$ is characterized by another Reynolds number

$$
\operatorname{Re}_{\mathrm{p}}=2 \omega a^{2} / v
$$

with $\omega=$ angular velocity of the particle. This Reynold number is lower than $I$ for a particle radius smaller than $4 \mu \mathrm{m}$. So, Stokes flow conditions prevail around the particles. Also, surface renewal [5] due to the scraping of the particles or penetration into the diffusion layer cannot explain the large increase of mass transfer.

The most acceptable model is based on the rotation of the particles in the diffusion layer [12-20], which is caused by the rotation component of the shear field in the viscous boundary layer. This effect can be expressed [12-14] in terms of an effective diffusion coefficient which is determined by the shear rate $(\dot{\gamma})$ and the volume fraction, $\phi$, of the particles.

The model of Hyman [15] is often used to calculate the limiting diffusion current [16-20]. For the rotating disc electrode this model predicts a linear $I_{1}-\Omega^{n}$ relation at high rotation speeds with $n=7 / 6[16,17,19]$. Caprani et al. [17] found experimentally that $n=0.5$ for both low and high rotation rates, while at the intermediate rates $n=$ about 0.6 was found. We also observed $n=0.5$ with $\mathrm{SiC}$ suspensions [22]. It is difficult to see how blockage of the electrode can explain this discrepancy.

Several investigations $[5,18,22]$ showed a threshold or critical value for the volume fraction, $\phi_{c}$, and also for the rotation speed, $\Omega_{c}$, above which particles affect the mass transfer. In this paper the effect of $\mathrm{SiC}$ particles on the mass transfer was studied with the rotating-disc electrode for the reduction of $\mathrm{K}_{3} \mathrm{Fe}(\mathrm{CN})_{6}$ and $\mathrm{ZnO}$ in alkaline solutions.

Hydrodynamic conditions, gravity direction to the electrode and particle size, were varied in order to investigate the effect on the critical values $\phi_{c}$ and $\Omega_{c}$. A new model is developed, in which rotation of the particles causes a decrease of the average diffusionlayer thickness, while the value of the diffusion coefficient is expected to be unaffected by the particles. For the rotating-disc this model predicts a $I_{1}-\Omega^{1 / 2}$ relation as given in the Levich equation, and an extra increase of the limiting current proportional to $\phi$. The occurrence of a critical value of $\Omega$ and $\phi$ is also explained.

\section{Experimental details}

An electrochemical cell with a volume of $100 \mathrm{ml}$ was used for the experiments. The electrolyte was $2 \mathrm{M}$ $\mathrm{KOH}$ with $0.05 \mathrm{M} \mathrm{ZnO}$ or with $0.05 \mathrm{M} \mathrm{K} \mathrm{K}_{3} \mathrm{Fe}(\mathrm{CN})_{6}$. The reference electrode for reduction of $\mathrm{ZnO}$ was an $\mathrm{Hg} / \mathrm{HgO}$ electrode; for the reduction of $\mathrm{K}_{3} \mathrm{Fe}(\mathrm{CN})_{6}$ a saturated calomel electrode was used; both were provided with a Luggin capillary. A platinum electrode of area $6 \mathrm{~cm}^{2}$ was used as the counter-electrode. Two platinum rotating-disc electrodes with radii $r_{\mathrm{E}}=3$ and $5 \mathrm{~mm}$ were used, the electrodes were polished with $\mathrm{Al}_{2} \mathrm{O}_{3}$ paste down to $0.05 \mu \mathrm{m}$. For the reduction of $\mathrm{K}_{3} \mathrm{Fe}(\mathrm{CN})_{6}$, a pyrolytic-graphite electrode with a radius of $4 \mathrm{~mm}$ was also used.

The average size of the $\mathrm{SiC}$ particles (arbitrary shape) for these experiments was determined from SEM photographs and is presented in Table 1. Before measurement a small quantity of powder was added to the electrolyte and stirred for about $5 \mathrm{~min}$ with a magnetic stirrer at the bottom of the cell. During the measurement, the magnetic stirring was stopped. The suspension was stirred between two measurements to avoid precipitation.

Table 1. Average size of the measured particle

\begin{tabular}{ll}
\hline Carborundum $(\mathrm{SiC})$ & \\
\hline Number & $\begin{array}{l}\text { Average particle diameter, } \\
2 a(\mu \mathrm{m})\end{array}$ \\
\hline 1200 & 3.0 \\
800 & 6.6 \\
500 & 12.2 \\
280 & 36.4 \\
150 & 85.0 \\
\hline
\end{tabular}




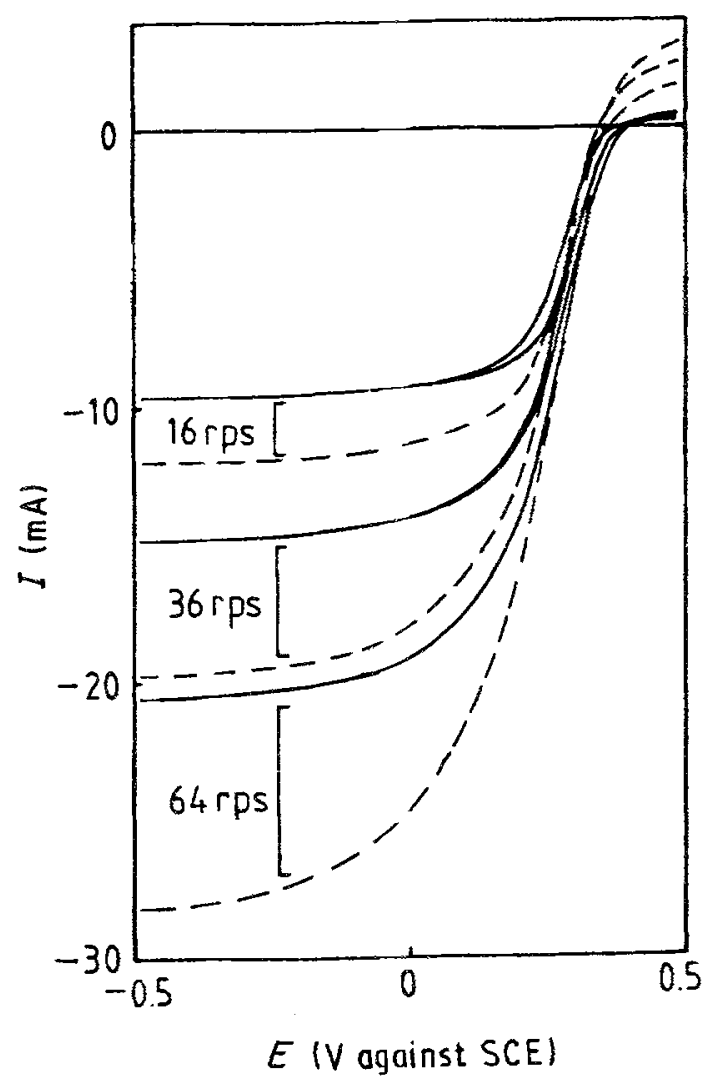

Fig. 1. Voltammograms of the reduction of $0.05 \mathrm{M} \mathrm{K}_{3} \mathrm{Fe}(\mathrm{CN})_{6}$ in $2 \mathrm{M} \mathrm{KOH}$ at a pyrolytic graphite RDE; rotation frequencies of 16 , 36 and 64 rps. (-) without particles (-) with $6 \mathrm{vol} \% \mathrm{SiC}$ particles of $6.6 \mu \mathrm{m}$ diameter.

Coagulation of the particles during the experiments was not observed.

\section{Results and discussion}

Fig. 1 shows the voltammogram for the reduction of $0.05 \mathrm{M} \mathrm{K}_{3} \mathrm{Fe}(\mathrm{CN})_{6}$ in $2 \mathrm{M} \mathrm{KOH}$ at the pyrolytic graphite electrode, the solid lines are measurements without particles; the dashed lines with $6 \mathrm{vol} \% \mathrm{SiC}$ particles with a diameter of $6.6 \mu \mathrm{m}$. The effect of

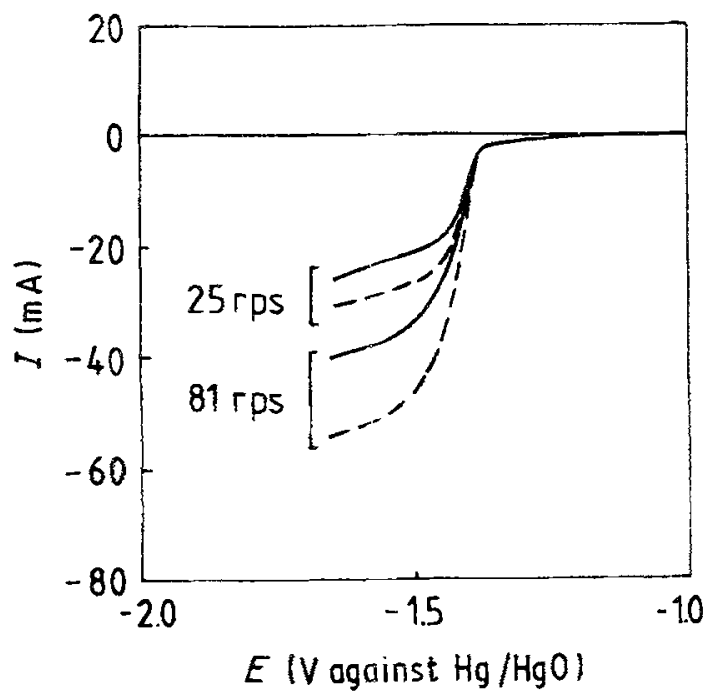

Fig. 2. Voltammograms of the reduction of $0.05 \mathrm{M} \mathrm{ZnO}$ in $2 \mathrm{M}$ $\mathrm{KOH}$ at a platinum RDE $\left(r_{\mathrm{E}}=4 \mathrm{~mm}\right)$; rotation frequencies of 25 and $81 \mathrm{rps}$. (-) without particles (- -) with $6 \mathrm{vol} \% \mathrm{SiC}$ particles of $6.6 \mu \mathrm{m}$ diameter.

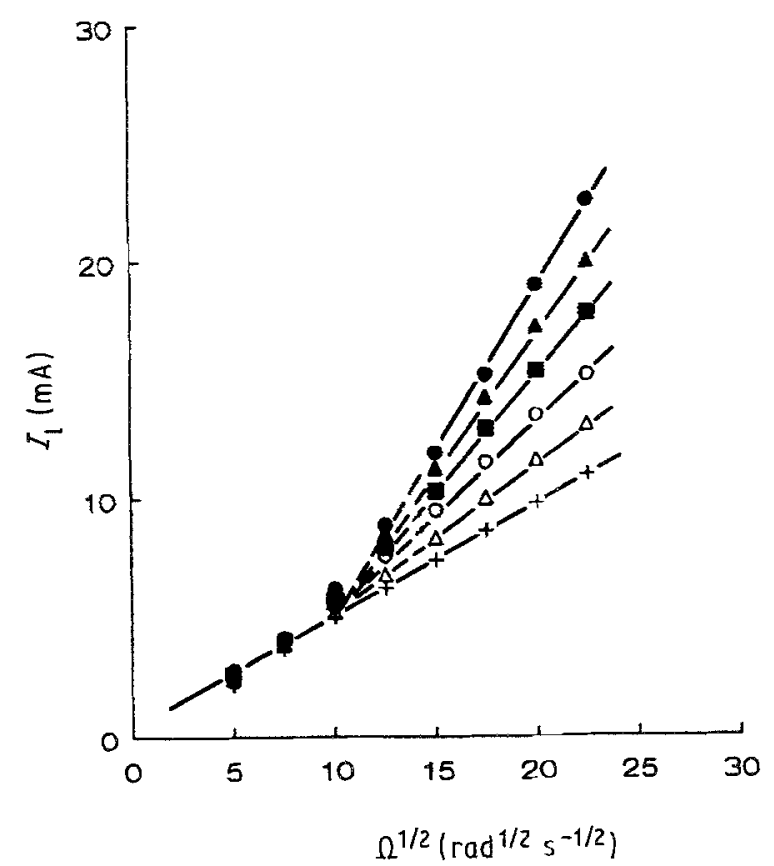

Fig. 3. Levich plot of the reduction of $0.05 \mathrm{M} \mathrm{K}_{3} \mathrm{Fe}(\mathrm{CN})_{6}$ in $2 \mathrm{M}$ $\mathrm{KOH}$ at a platinum $\mathrm{RDE}\left(r_{\mathrm{E}}=3 \mathrm{~mm}\right)$ with the following volune fractions (vol\%) of $\mathrm{SiC}$ particles of $6.6 \mu \mathrm{m}$ diameter: $(+) 0(\Delta) 6$ (O) $10(\mathbf{m}) 15(\mathbf{A}) 20(\bullet) 25$.

$6 \mathrm{vol} \% \mathrm{SiC}$ on the reduction of $\mathrm{ZnO}$ at a platinum electrode is presented in Fig. 2. Both figures show an increased mass transfer after addition of the $\mathrm{SiC}$ particles. In Fig. 3 the Levich plot $\left(I_{1}-\Omega^{1 / 2}\right)$ is given for the reduction of $K_{3} \mathrm{Fe}(\mathrm{CN})_{6}$ for different volume fractions of the particles; the influence of the volume fraction on the limiting current is seen in Fig. 4. In Figs 5 and 6 the limiting current is plotted as a function of the square root of the rotation speed and the volume fraction. In this experiment the disc radius, $r_{E}$, is $5 \mathrm{~mm}$ and the SiC particle diameter is $12.2 \mu \mathrm{m}$. In Figs 3 and 5 the Levich equation is obeyed from zero to low SiC content; at higher volume fractions, a

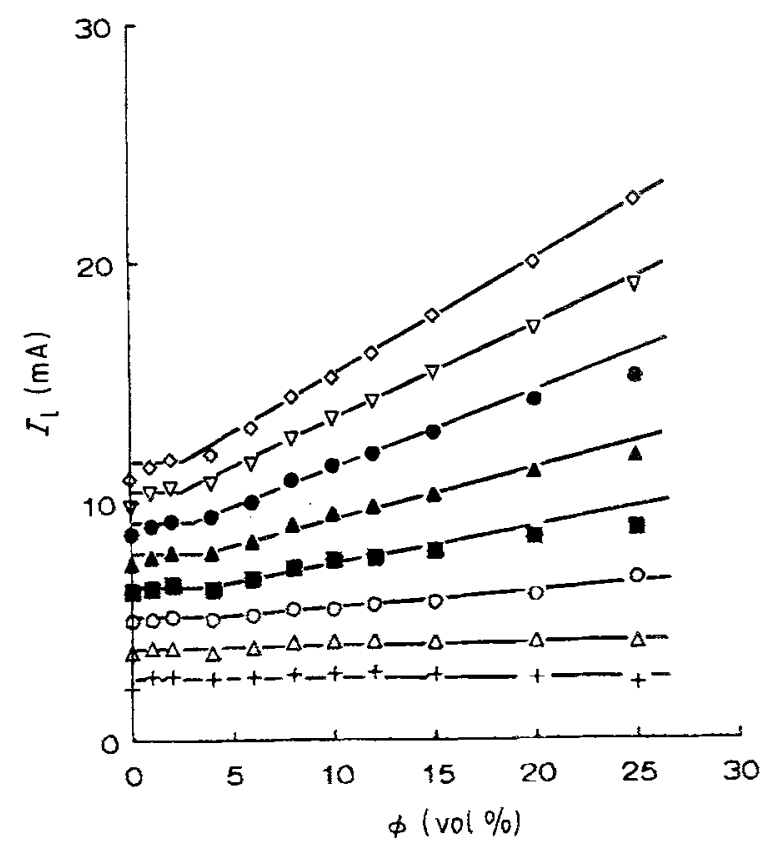

Fig. 4. Limiting current (taken from the data of Fig. 3) as a function of the volume fraction $(\phi)$ at rotation frequencies in rps of $(+) 4$ $(\Delta) 9(0) 16(\square) 25(\Delta) 36(\bullet) 49(\nabla) 64(0) 81$. 


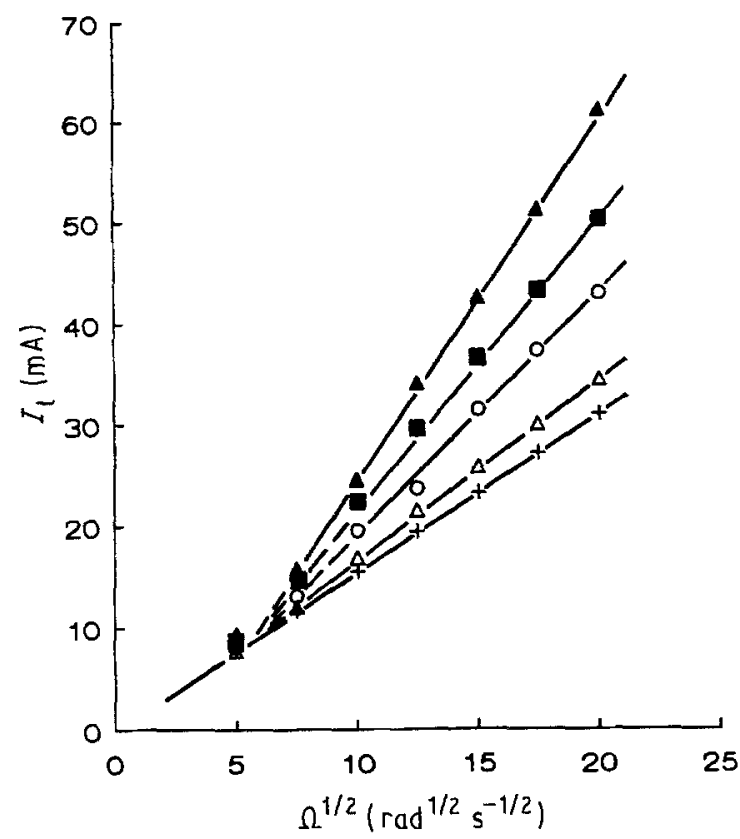

Fig. 5. Levich plot of the reduction of $0.05 \mathrm{M} \mathrm{K}_{3} \mathrm{Fe}(\mathrm{CN})_{6}$ in $2 \mathrm{M}$ $\mathrm{KOH}$ at a Pt-RDE $\left(r_{\mathrm{E}}=5 \mathrm{~mm}\right)$ with the following fractions ( $\mathrm{vol} \%$ ) of SiC particles of $12.2 \mu \mathrm{m}$ diameter: $(+) 0(\Delta) 5(O) 10(\mathbb{D}) 15$ (ム) 20 .

critical rotation frequency, $\Omega_{c}$, is observed, above which the enhanced mass-transfer is seen. Above $\Omega_{c}$ the slope increases with an increasing volume fraction of the particles. In Figs 4 and 6 also a critical value for the volume fraction, $\phi_{c}$, is also observed. It thus appears that only above $\Omega_{\mathrm{c}}$ and $\phi_{\mathrm{c}}$ do particles increase the mass transfer.

The effect of particle size was investigated for $\mathrm{SiC}$ particles with diameters 6.6, 12.2 and $36.4 \mu \mathrm{m}$. In Figs 7-9 the limiting current for the reduction of $\mathrm{K}_{3} \mathrm{Fe}(\mathrm{CN})_{6}$ is depicted as a function of $\Omega^{1 / 2}$ and in Figs $10-12$ as a function of the volume fraction.

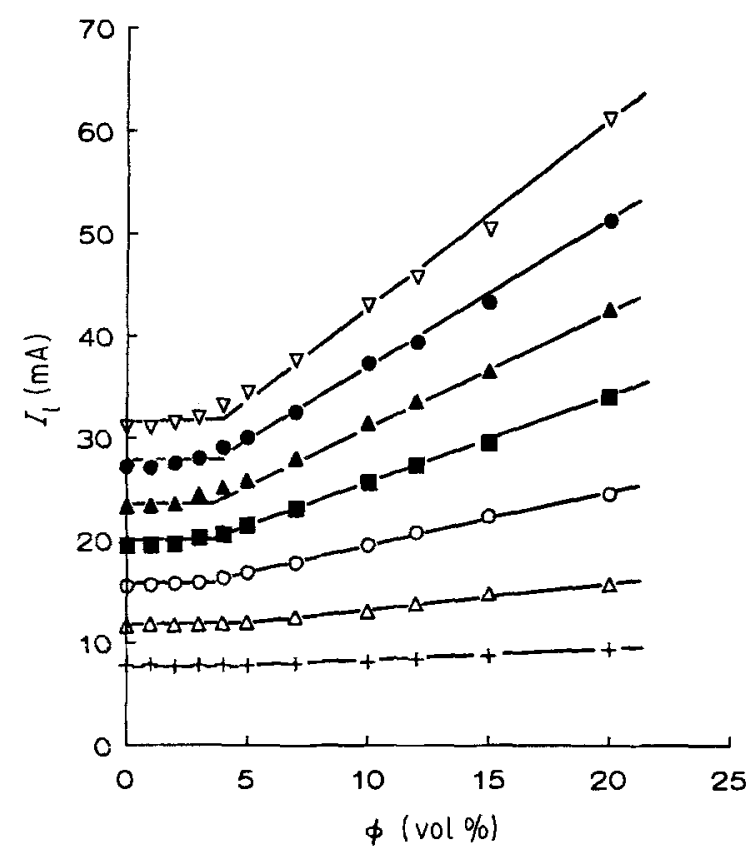

Fig. 6. Limiting current (taken from the data of Fig. 5) as a function of the volume fraction $(\phi)$ at rotation frequencies in rps of $(+) 4$ $(\Delta) 9(0) 16(\bullet) 25(\Delta) 36(\bullet) 49(\nabla) 64$

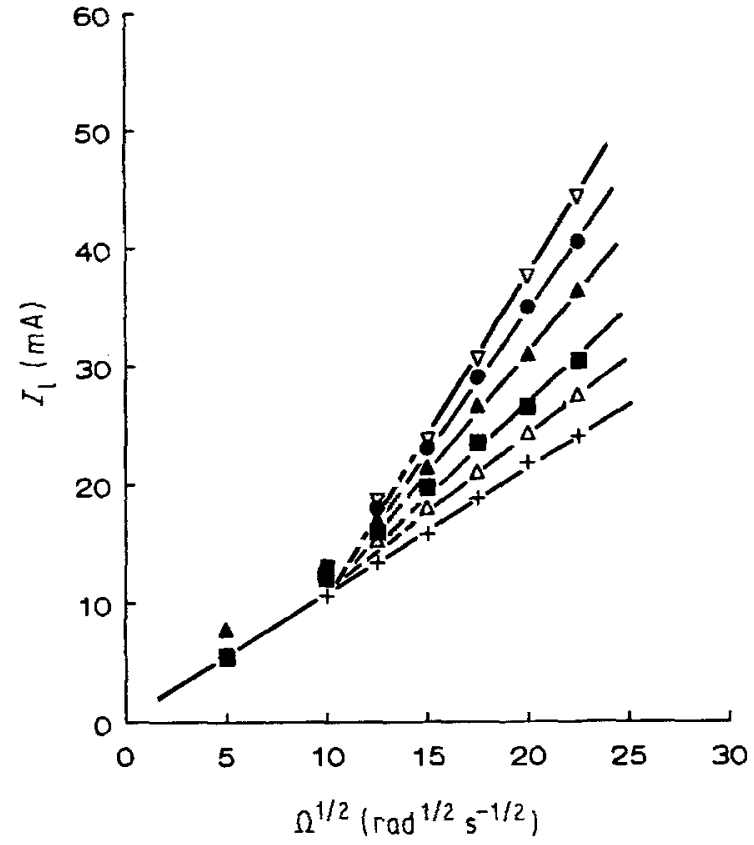

Fig. 7. Levich plot of the reduction of $\mathrm{K}_{3} \mathrm{Fe}(\mathrm{CN})_{6}$ at a pyrolytic graphite $\operatorname{RDE}\left(r_{\mathrm{F}}=4 \mathrm{~mm}\right)$ with the following fractions (vol\%) of $\mathrm{SiC}$ particles of $6.6 \mu \mathrm{m}$ diameter: $(+) 0(\Delta) 3(\boldsymbol{\bullet}) 6(\Delta) 11(\bullet) 16$ ( $\nabla) 20$.

\section{The model}

In Fig. 13a the hydrodynamic conditions adjacent to an electrode are depicted. In this layer with thickness $\delta_{\mathrm{P}}$ a shear rate $\dot{\gamma}=\mathrm{d} v / \mathrm{d} z$ exists, which can be seen as the sum of a pure streaming motion $\left(v_{\mathrm{s}}\right)$ and a rotational flow field with angular rotation frequency $\omega_{0}=\frac{1}{2} \dot{\gamma}$. If microscopic particles are present in the electrolyte flow along an electrode surface, this rotational flow field also induces a particle rotation, $\omega_{0}=\frac{1}{2} \dot{\gamma}$, due to the viscous forces (Fig. 13b). The torque ( $T$ ) acting on a spherical particle with radius $a$ is, according to

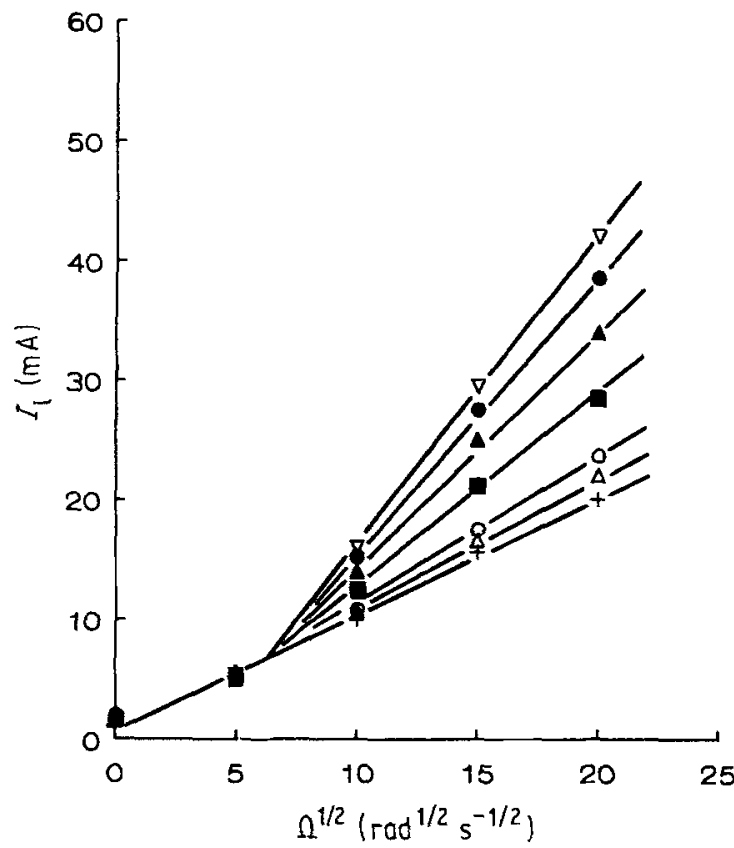

Fig. 8. Levich plot of the reduction of $\mathrm{K}_{3} \mathrm{Fe}(\mathrm{CN})_{6}$ at a pyrolytic graphite RDE $\left(r_{\mathrm{E}}=4 \mathrm{~mm}\right.$ ) with the following fractions ( $\mathrm{vol} \%$ ) of SiC particles of $12.2 \mu \mathrm{m}$ diameter: $(+) 0(\Delta) 4(0) 6(\mathbb{0}) 11(\mathbf{\Delta}) 16$ 


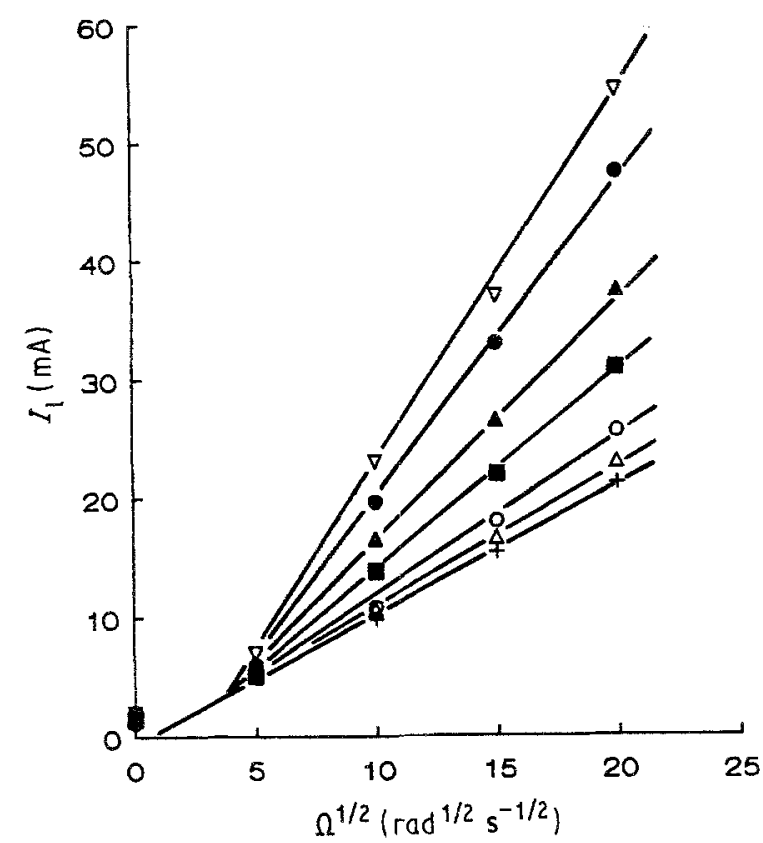

Fig. 9. Levich plot of the reduction of $\mathrm{K}_{3} \mathrm{Fe}(\mathrm{CN})_{6}$ at a pyrolytic graphite $\operatorname{RDE}\left(r_{\mathrm{E}}=4 \mathrm{~mm}\right)$ with the following fractions $(\mathrm{vol} \%)$ of $\mathrm{SiC}$ particles of $36.4 \mu \mathrm{m}$ diameter: $(+) 0(\Delta) 6(0) 10(\mathbf{D}) 16(\Delta)$ $20(\bullet) 25(\nabla) 29$.

Brenner [23]

$$
T=64 \pi \eta a^{3}\left(\omega_{0}-\omega\right) .
$$

with $\eta=$ dynamic viscosity. This torque gives the particle, with moment of inertia $J$ an angular acceleration $\dot{\omega}$

$$
T=\dot{\omega} J
$$

The moment of inertia of a spherical particle is

$$
J=(8 / 15) \pi a^{5} \rho
$$

with $\rho=$ density of particle. So it follows from Equations 3-5 that

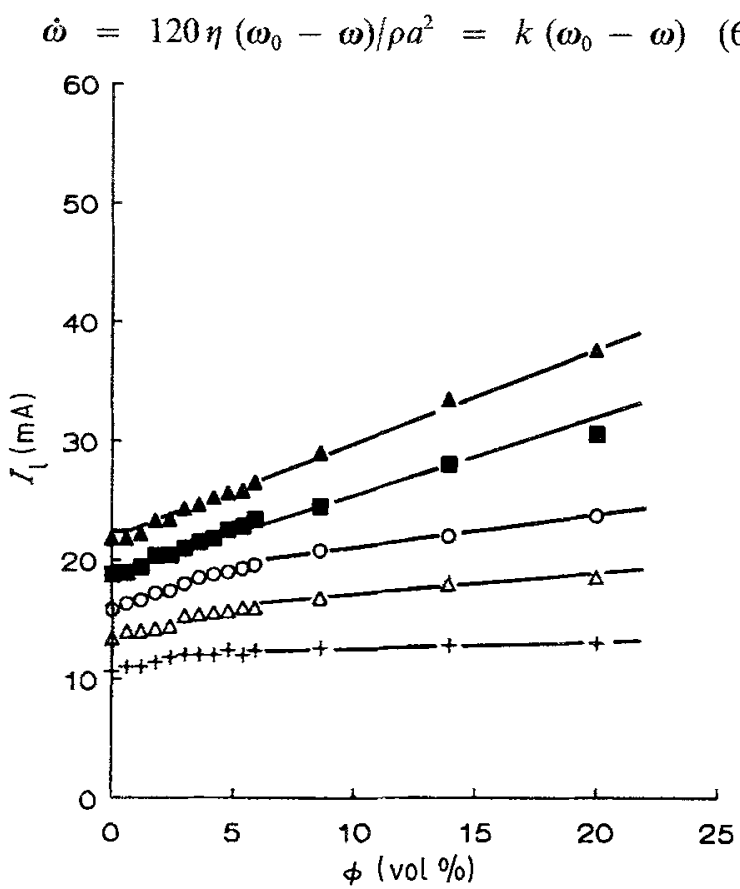

Fig. 10. Limiting current as a function of the volume fraction $(\phi)$ of $6.6 \mu \mathrm{m} \mathrm{SiC} \mathrm{particles} \mathrm{at} \mathrm{rotation} \mathrm{frequencies} \mathrm{in} \mathrm{rps} \mathrm{of}(+) 16(\Delta)$ 25 (0) 36 (u) 49 (4) 64

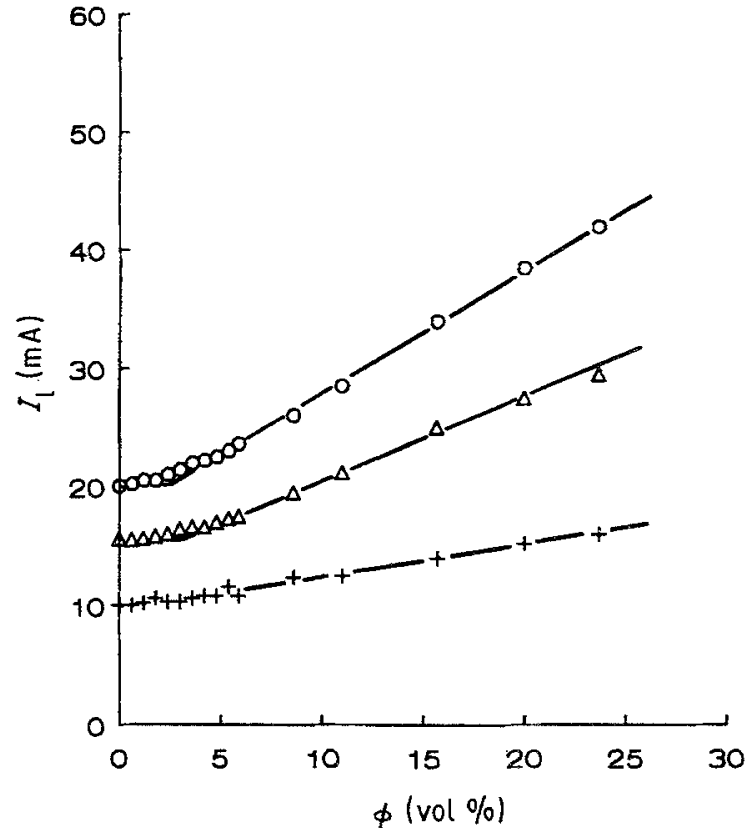

Fig. 11. Limiting current as a function of the volume fraction $(\phi)$ of $12.2 \mu \mathrm{m} \mathrm{SiC}$ particles at rotation frequencies in rps of $(+) 16(\Delta)$ 36 (O) 64 .

with $k=120 \eta / \rho a^{2}$. The solution of this differential equation is:

$$
\omega=\omega_{0}\left(1-\mathrm{e}^{-k t}\right)
$$

For particles with a radius smaller than $20 \mu \mathrm{m}$, $\rho=3000 \mathrm{~kg} \mathrm{~m}^{-3}$ and $\eta=1.2 \times 10^{-3} \mathrm{~kg} \mathrm{~s}^{-1} \mathrm{~m}^{-1}$, the time constant, $k$, is larget than $10^{5} \mathrm{~s}^{-1}$. This implies that at the rotation frequency $\omega_{0}=\frac{1}{2} \dot{\gamma}$, the particles rotate within about $10 \mu$ s after entry. Due to this short response time the particles rotate at a frequency of about $\omega_{0}$ and notwithstanding the short time, ( $\sim 200 \mathrm{~ms}$ ) the particles actually pass along the RDE surface.

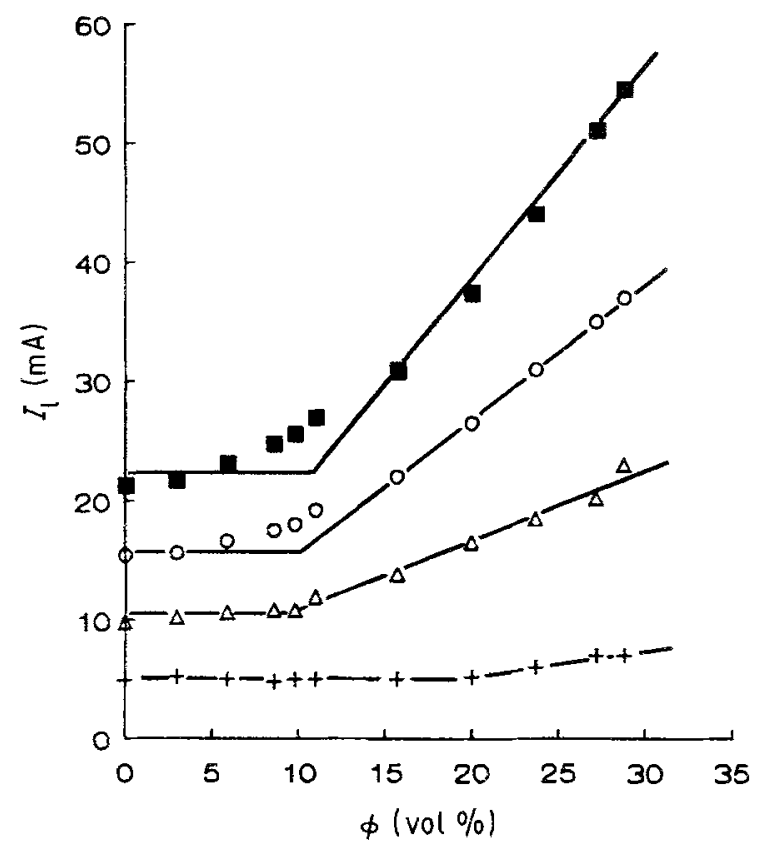

Fig. 12. Limiting current as a function of the volume fraction $(\phi)$ of $36.4 \mu \mathrm{m} \mathrm{SiC}$ particles at rotation frequencies in rps of $(+) 4(\Delta)$ $16(0) 36(\square) 64$ 

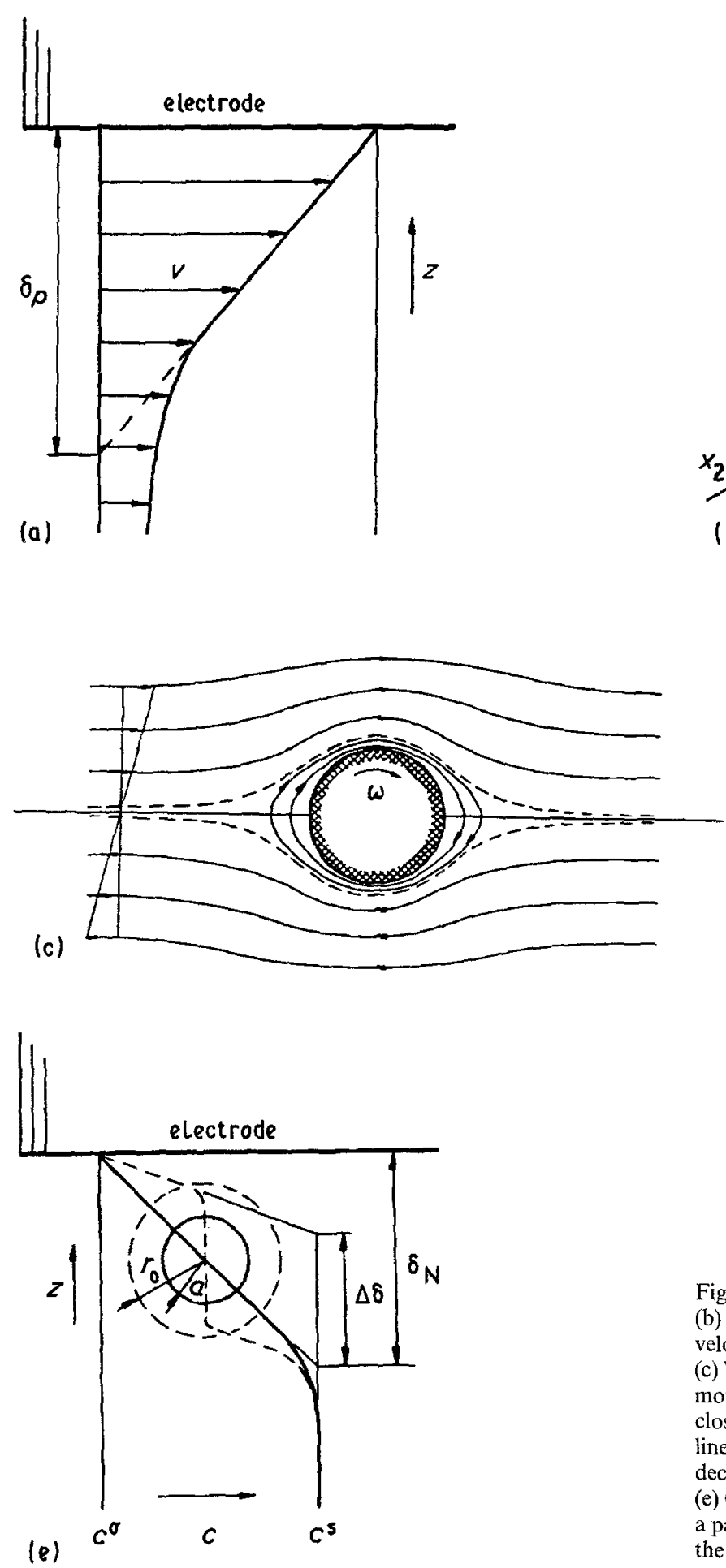

The velocity disturbance $(u)$ of the rotating particles, besides the normal shear field, $v$, can be calculated using an expression given by Batchelor [24]. This flow field is superposed on the normal existing field, $\boldsymbol{v}$, in the viscous boundary layer. For one velocity direction, $u_{i}$

$$
u_{i}=-e_{i j} x_{j}\left(\frac{a}{r}\right)^{5}+\frac{5}{2} e_{j k} x_{i} x_{j} x_{k}\left[\left(\frac{a}{r}\right)^{7}-\left(\frac{a}{r}\right)\right]^{5}
$$

with

$$
e_{i j}=\frac{1}{2}\left(\frac{\partial v_{i}}{\partial x_{j}}+\frac{\partial v_{j}}{\partial x_{i}}\right)
$$

$e$ is the shear rate and $x_{i}$ is the distance in one direction from the centre of the particle.

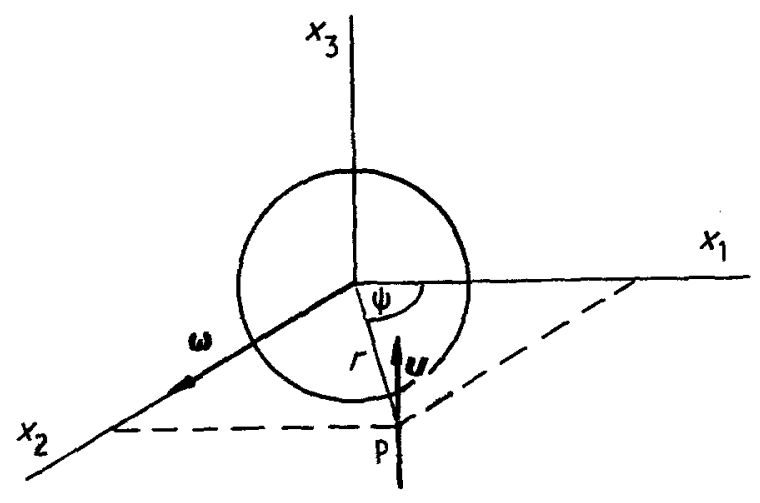

(b)

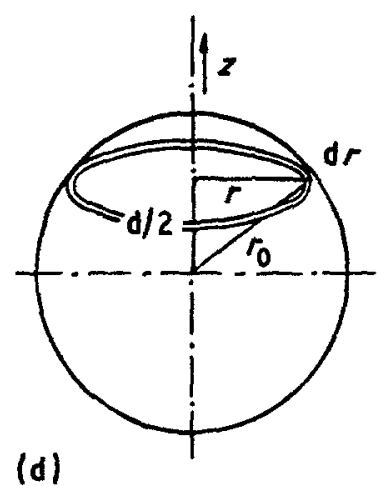

Fig. 13. (a) Hydrodynamic boundary layer $\delta_{p}$ at an electrode. (b) Rotating speed $(\omega)$ in the $x_{2}$-direction of a particle with a velocity disturbance $(\boldsymbol{u})$ in the $x_{1}-x_{2}$ plane and $x_{3}=z=0$. (c) Velocity field around a rotating particle with radius $a$ (coordinates moving along with the particle translation velocity). Domains of closed and open streamlines are seen, separated with the broken line. (d) Sphere with radius $r_{0}$ of increased mass transfer. The decrease of the diffusion layer is $d$ for the ring with a surface $2 \pi r \mathrm{~d} r$. (e) Concentration profile of the active ions at an electrode. Without a particle the diffusion layer thickness is $\delta_{\mathrm{N}}$; with a rotating particle, the layer thickness becomes $\delta_{\mathrm{N}}-\Delta \delta$.

The velocity disturbance component, $u_{3}$, in the $z$ direction contributes to an extra mass transfer to the electrode (see Fig. 13b). Considering simple shear conditions in one direction $v_{1}=\dot{\gamma} x_{3}, v_{2}=0$ and $v_{3}=0$ this gives only two shear rate components

$$
e_{13}=e_{31}=\frac{1}{2}\left(\frac{\partial v_{1}}{\partial x_{3}}+\frac{\partial v_{3}}{\partial x_{1}}\right)=\frac{1}{2} \dot{\gamma}
$$

At the point $\mathrm{P}$ in Fig. 13b, $x_{1}=r \cos \psi, x_{2}=r \sin \psi$ and $x_{3}=0$ and the disturbance velocity becomes

$$
\begin{aligned}
u_{3} & =e_{3 j} x_{j}\left(\frac{a}{r}\right)^{5}=-e_{31} x_{1}\left(\frac{a}{r}\right)^{5} \\
& =-\frac{1}{2} j r\left(\frac{a}{r}\right)^{5} \cos \psi
\end{aligned}
$$


For the total disturbance velocity, $\boldsymbol{u}$, we can also write:

$$
\boldsymbol{u}=-\left(\boldsymbol{\omega}_{0} \times \boldsymbol{r}\right)\left(\frac{a}{r}\right)^{5} \cos \psi
$$

The disturbance, $\boldsymbol{u}$, evoked by strain forces on the particle, gives a different flow pattern around a particle in the viscous boundary layer [25] as shown in Fig. 13c. Domains of closed and open streamlines are seen, separated at the broken line in this figure. In the domain of closed streamlines the reactants are well mixed.

Due to the rapid decrease of the velocity disturbance $|\boldsymbol{u}|$ with the distance to the particle, the domain will be small compared with the particle size, therefore film transport of the reactant at the particle surface can be assumed (see Figs. 13c). Due to the reaction of the active species, a concentration gradient exists in the $z$ direction to the electrode surface. For the particles in this diffusion layer an average concentration is assumed in the domains of closed streamlines (Fig. 13c). This results in a local decrease of the diffusion layer thickness, $d$, which depends on the distance, $r$, from the $z$ axis of the particle in Fig. 13d. In this figure $r_{0}$ is the distance to the centre of the particle where $|\boldsymbol{u}|$ is equal to the rate of mass transfer of the reactants without particles. For a radius greater than $r_{0}$ no increase of mass transfer exists. The average thinning, $\bar{d}$, of the diffusion layer for a film thickness $\left|r_{0}-a\right|$ around the particle is

$$
\bar{d}=\frac{\int_{0}^{r_{0}} d(r) 2 \pi r \mathrm{~d} r}{\int_{0}^{r_{0}} 2 \pi \mathrm{d} r}=\frac{4 \pi \int_{0}^{r_{0}}\left(r_{0}^{2}-r^{2}\right)^{\frac{1}{2}} r \mathrm{~d} r}{2 \pi \int_{0}^{r_{0}} r \mathrm{~d} r}=\frac{4}{3} r_{0}
$$

This holds for the cross-sectional area of the particle $A_{\mathrm{p}}=\pi r_{0}^{2}$.

For an electrode surface $A_{\mathrm{E}}=\pi r_{\mathrm{E}}^{2}$, the average thinning for $N$ particles in the diffusion layer is

$$
\Delta \delta=\frac{4}{3} r_{0} \frac{A_{\mathrm{p}}}{A_{\mathrm{E}}}=\frac{4 r_{0}^{3} N}{3 r_{\mathrm{E}}^{2}}
$$

Fig. $13 \mathrm{e}$ presents the concentration profile at an electrode, with and without particles. It is assumed that one particular particle does not disturb the velocity distribution around other particles, and that the particle size is smaller than the diffusion layer thickness $\left(2 a<\delta_{\mathrm{N}}\right)$. The volume fraction of the particles can be expressed by $\phi=V_{\mathrm{d}} /\left(V_{0}+V_{\mathrm{d}}\right)$, where $V_{\mathrm{d}}$ is the total particle volume and $V_{0}$ is the volume of the liquid. The number of particles, $N$, is defined as

$$
N=\frac{M}{M_{\mathrm{p}}}=\frac{\phi V_{0}}{\frac{4}{3} \pi a^{3}(1-\phi)}
$$

with $M=$ total mass of all particles in the diffusion layer and $M_{\mathrm{p}}=$ the mass of one particle.

Only particles present in the diffusion layer increase the mass transfer; the volume of this layer is $V_{0}=\pi r_{\mathrm{E}}^{2} \delta_{\mathrm{N}}(1-\phi)$, therefore

$$
N=\frac{\pi \phi r_{\mathrm{E}}^{2} \delta_{\mathrm{N}}}{\frac{4}{3} \pi a^{3}}
$$

Substitution in Equation 14 leads to

$$
\frac{\Delta \delta}{\delta_{\mathrm{N}}}=\left(\frac{r_{0}}{a}\right)^{3} \phi
$$

The relative decrease of the diffusion-layer thickness is thus proportional to the volume fraction of the particles in this layer and the ratio $r_{0} / a$.

The limiting current is given by

$$
I_{3}=n F A_{\mathrm{E}} D c^{\mathrm{s}} / \delta_{\mathrm{N}}
$$

For an RDE

$$
I_{1}=B \Omega^{1 / 2}
$$

with

$$
B=0.62 n F A_{\mathrm{E}} D^{2 / 3} v^{-1 / 6} c^{\mathrm{s}}
$$

Reduction of the diffusion layer by the spinning particles is $\delta_{\mathrm{N}}-\Delta \delta$, so with Equations 18 and 19

$$
I_{1}=B \Omega^{1 / 2} /\left(1-\Delta \delta / \delta_{\mathrm{N}}\right)
$$

Substitution from Equation 17 gives

$$
I_{1}=B \Omega^{1 / 2} /\left[1-\left(\frac{r_{0}}{a}\right)^{3} \phi\right]
$$

This expression is only valid for a low fraction of particles. Then no overlap of the space domain of the rotating particles is considered. Expansion in a Taylor series and neglecting higher terms yields

$$
I_{1}=B \Omega^{1 / 2}\left[1+\left(\frac{r_{0}}{a}\right)^{3} \phi\right]
$$

The limiting current can thus be expressed as a modified Levich equation which takes into account the volume fraction, $\phi$, of the particles and the ratio $r_{0} / a$.

Figs 4 and 6 show a linear relationship between $I_{1}$ and $\phi$ in good agreement with Equation 23. Plots of the experimental results according to Equation 22, however, do not yield a straight line. It seems that the error introduced by going from Equation 22 to Equation 23 is compensated.

This could be due to the overlap of the space domains of the rotating particles, in particular at higher volume fractions.

This model does not predict the appearance of the critical values in $\Omega$ and $\phi$ as measured in Figs 3-12. Four explanations of the origin of the values $\Omega_{c}$ and $\phi_{c}$ will now be further investigated

1. Changes in hydrodynamic conditions.

2. Gravity forces which cause precipitation.

3. Critical peripheral rotation velocity of the rotating particle which is proportional to the particle size.

4. Adhesion of the particles to the electrode and blockage of the electrode.

\subsection{Hydrodynamic conditions}

The ratio of the inertial forces and viscous forces of the mass flow near the electrode may be crucial. This is characterized by the Reynolds number of the elec- 
Table 2. Parameters and results for two disc-electrode experiments

\begin{tabular}{lcr}
\hline Parameter & Experiment 1 & Experiment 2 \\
\hline Particle size, $2 a(\mu \mathrm{m})$ & 6.6 & 12.2 \\
Electrode radius, $r_{\mathrm{E}}(\mathrm{mm})$ & 3.0 & 5.0 \\
Outer electrode radius, $r_{\mathrm{o}}(\mathrm{mm})$ & 6.2 & 13.0 \\
\hline Results & & \\
\hline Critical rotation speed, $\Omega_{\mathrm{c}}^{\mathrm{i} / 2}\left[\left(\mathrm{rad} \mathrm{s}^{-1}\right)^{1 / 2}\right]$ & 10.0 & 5.1 \\
${\text { Critical volume fraction, } \phi_{\mathrm{c}}(\mathrm{vol} \%)}^{2}$ & 2.5 & 3.8 \\
\hline
\end{tabular}

trode $\operatorname{Re}_{\mathrm{E}}=2 \Omega r_{\mathrm{E}}^{2} / \nu$, and of the particle $\operatorname{Re}_{\mathrm{p}}=$ $2 \omega a^{2} / v$. To establish this effect on $\Omega_{c}$ and $\phi_{c}$, the limiting current was compared for two systems under similar hydrodynamic conditions, Figs 3 and 4 and Figs 5 and 6. In these experiments two disc electrodes were used with radii $r_{\mathrm{E} 1}$ and $r_{\mathrm{E} 2}$ and two different particle sizes. The particle sizes were chosen such that the ratios $\mathrm{Re}_{\mathrm{E}} / \mathrm{Re}_{\mathrm{p}}$ were the same for both systems. This requires $a_{1} / a_{2}=r_{\mathrm{E} 1} / r_{\mathrm{E} 2}$ at the same rotation frequency.

Because the hydrodynamic conditions also depend on the outer radius $r_{0}$ of the electrode, $a_{1} / a_{2}=$ $r_{\mathrm{E} 1} / r_{\mathrm{E} 2}=r_{\mathrm{o} 1} / r_{\mathrm{o} 2}$. The parameters and results of both experiments are summarized in Table 2.

For the same ratio of inertial/viscous forces in the boundary layer, the critical frequency, $\Omega_{c}$, and critical volume fraction, $\phi_{c}$, for both experiments differ. This excludes the hydrodynamic effect as being responsible for the appearance of the values $\Omega_{c}$ and $\phi_{c}$.

\subsection{Gravitation}

The influence of gravitation on the appearance of a

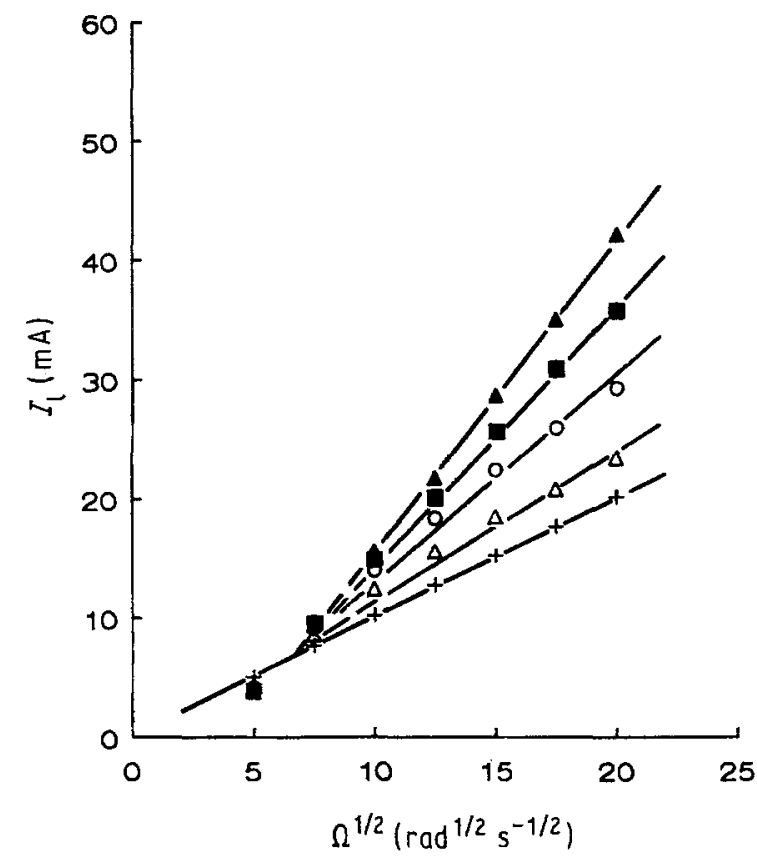

Fig. 14. Levich plot of the reduction of $0.05 \mathrm{M} \mathrm{K}_{3} \mathrm{Fe}(\mathrm{CN})_{6}$ in $2 \mathrm{M}$ $\mathrm{KOH}$ in an upside-down cell at a pyrolytic graphite RDE $\left(r_{\mathrm{E}}=\right.$ $4 \mathrm{~mm}$ ) with the following fractions (vol\%) of SiC particles of $6.6 \mu \mathrm{m}$ diameter: $(+) 0(\Delta) 5(0) 10(\mathbb{\square}) 15(\Delta) 20$. critical volume fraction was investigated in an upsidedown cell: a $200 \mathrm{ml}$ cell in which the RDE was mounted at the bottom. Six small $(1 \mathrm{~cm}$ wide $\times 5 \mathrm{~cm}$ high) baffles were inserted in the upper part of the cell to prevent a strong circulation of electrolyte and sucking of air to the electrode. A small stirrer in the upper part of the cell prevented precipitation of the suspension. For these experiments, a pyrolytic graphite RDE with a radius of $4 \mathrm{~mm}$ was used and $\mathrm{SiC}$ particle sizes of 6.6 and $12.2 \mu \mathrm{m}$. The results for the limiting current as a function of the rotation speed and the volume fraction are shown in Figs 14-17. In Figs 15 and 17, a critical volume fraction, $\phi_{c}$, is absent, however a critical rotation speed, $\Omega_{c}$, is observed (Figs 14 and 16).

In Figs 15 and 17, the drawn lines are the best fit of Equation 23 with $r_{\mathrm{o}} / a=1.65$. As can be seen from both figures, the model gives a good agreement for the higher rotation speeds, $\Omega>\Omega_{\mathrm{c}}$. For the experiment with a particle size of $12.2 \mu \mathrm{m}$, the diffusion layer thickness $\delta_{N}=7 \mu \mathrm{m}$ for a rotation speed of $64 \mathrm{rps}$, which indicates that in this case, for a particle size larger than the diffusion layer thickness, the model

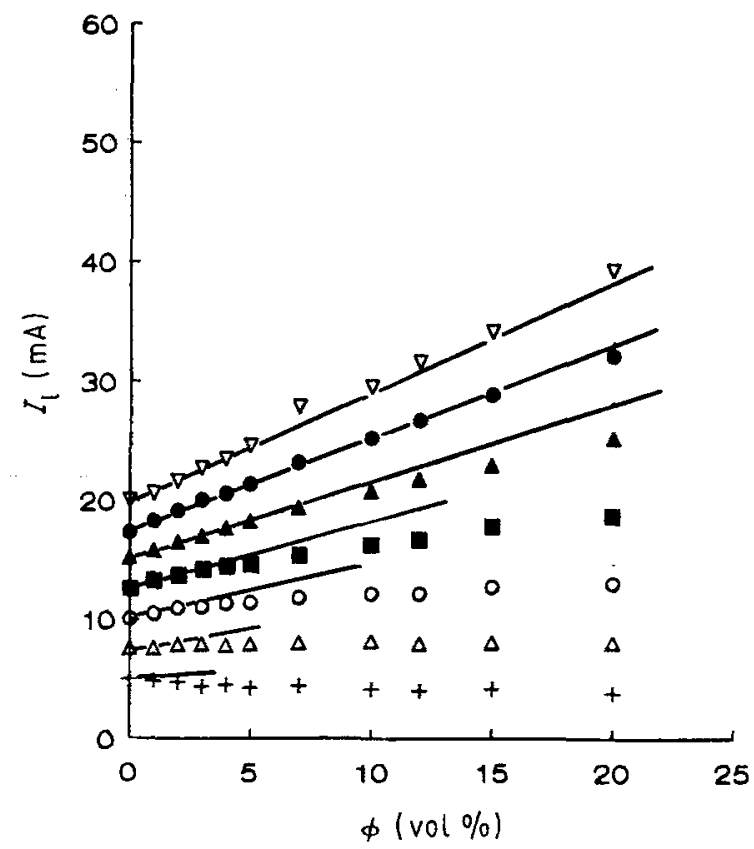

Fig. 15. Limiting current (taken from the data of Fig. 14) as a function of the volume fraction $(\phi)$ at rotation frequencies in rps of $(+) 4(\Delta) 9(0) 16(\square) 25(\Delta) 36(\bullet) 49(\nabla) 64$. The drawn lines are fitted with Equation 23 


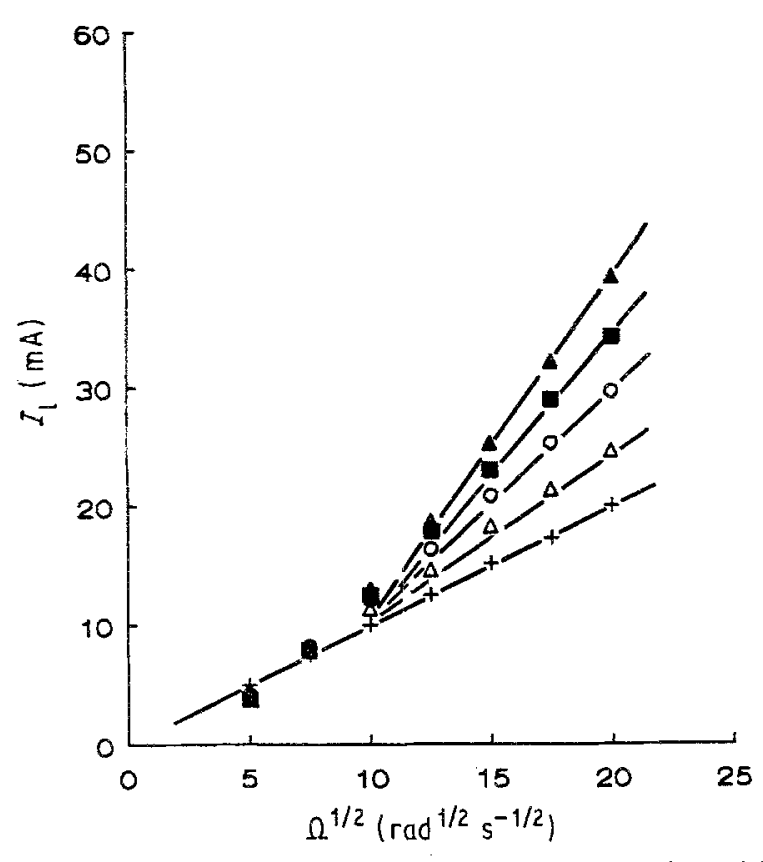

Fig. 16. Levich plot of the results with an upside-cell with particle diameter of $12.2 \mu \mathrm{m}$ (other data and key as in Fig. 14).

does not fully agree with the experimental results (Fig. 17).

The gravitational force acting on a particle with radius $a$ in suspension is

$$
F_{\mathrm{g}}=\frac{4}{3} \pi a^{3} \Delta \rho g
$$

with $\Delta \rho=$ the difference between particle density and the liquid density. This force induces a precipitation of the particles. For dilute suspensions, the precipitation velocity is retarded by the Stokes force

$$
F_{\mathrm{S}}=6 \pi \eta a \Delta v
$$

$\Delta v=$ the difference between the particle velocity and the liquid velocity. At a distance to the electrode that is comparable with the viscous boundary-layer thick-

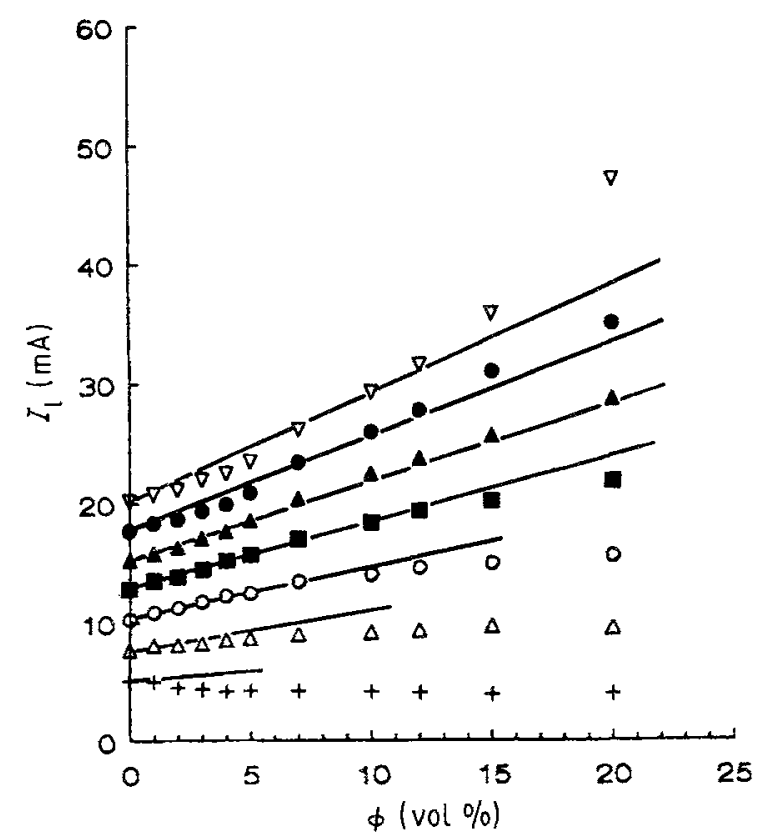

Fig. 17. Limiting current (taken from the data of Fig. 16) as a function of the volume fraction $(\phi)$ at the same rotation frequencies. See Fig. 15 for key. The drawn lines are fitted with Equation 23 . ness, $\delta_{\mathrm{P}}$, a small pressure gradient $\mathrm{d} p / \mathrm{d} z$ causes an extra force $\left(F_{\mathrm{p}}\right)$ on the particles

$$
F_{\mathrm{p}}=\frac{4}{3} \pi a^{3} \frac{\mathrm{d} p}{\mathrm{~d} z}
$$

The viscous and pressure forces are in equilibrium with the gravitational force

$$
F_{\mathrm{g}}-F_{\mathrm{s}}+F_{\mathrm{p}}=0
$$

This yields the precipitation velocity

$$
\Delta v=\frac{2}{9} \frac{a^{2}}{\eta}\left(\Delta \rho g+\frac{\mathrm{d} p}{\mathrm{~d} z}\right)
$$

The mass transfer at an RDE depends strongly on the electrolyte flow to the electrode, i.e. the flow in the axial direction, $v_{z}$. This flow only depends on the $z$ coordinates of the electrode and is $v_{z}=(\Omega v)^{1 / 2} H(\zeta)$ [21] where $H(\xi)$ is a dimensionless velocity depending on the dimensionless distance to the electrode $\xi=$ $(\Omega / v)^{1 / 2}$. For small distances $z \leqq \delta_{\mathrm{p}}$, the axial velocity is a parabolic function of the distance [21]

$$
v_{z}=0.51 \Omega^{3 / 2} v^{-1 / 2} z^{2}
$$

For an electrode facing down, the particles cannot always reach the electrode surface. Then in the centre of the RDE $(r=0)$, the particles are at the minimal approach distance to the RDE because the radial and angular velocities are zero.

At this smallest distance, $z_{0}$, the upward velocity, $v_{z}$, is equal to the precipitation velocity, $\Delta v$. From Equations 28 and 29 it follows

$$
z_{0}=-0.66 \frac{a v^{1 / 4}}{\eta^{1 / 2} \Omega^{3 / 4}}\left(\Delta \rho g+\frac{\mathrm{d} p}{\mathrm{~d} z}\right)^{1 / 2}
$$

The minimal approach distance, $z_{0}$, is proportional to the radius, $a$, of the particle. For an SiC particle with radius $a=2.5 \mu \mathrm{m}, z_{0}=3.5 \mu \mathrm{m}$ at a rotation speed $\Omega=314 \mathrm{rads}^{-1}$. The distance between particle and electrode is comparable with the diffusion-layer thickness, $\delta_{\mathrm{N}}$, therefore these particles cannot influence the mass transfer to the electrode. This explains why no influence of the particles is observed at low volume fractions in Figs 4 and 6.

Roha [5] has numerically calculated the minimal distance between particles and the RDE for a suspension of glass spheres and called this the 'static approach distance'. Because of such a region without particles, there will be a region with an increased number of particles at larger distance and it can be argued that this 'condensed layer' has fluidised-bed properties. With increasing volume fractions of particles of this fluidised bed, the fall-velocity of the particles according to the Stokes equation will decrease with a factor $K(\phi)$.

This correction $K(\phi)$ depends on the volume fraction of the particles and is the result of the increased viscosity and hindrance by other particles. This correction can be derived from the relation given by Barnea and Mizraki [26]. Instead of the bed expansion, $\varepsilon, K$ is given here as a function of the 
volume fraction, $\phi$

$$
K(\phi)=\frac{(1-\phi)^{2}}{\left(1+\phi^{1 / 3}\right) \exp [5 \phi / 3(1-\phi)]}
$$

By adding more particles, the volume fraction increases and the volume fraction of the particles in the condensed layer becomes higher than the bulk value. This effect together with $K(\phi)$ gives an extra increase of the volume fraction of particles in the condensed layer and results in a strongly reduced fall-velocity of the particles and hence a smaller $z_{0}$.

If $z_{0}$ becomes smaller than $\delta_{\mathrm{N}}$, the particles also affect the diffusion boundary-layer and thus the mass transfer. So there will be a critical volume fraction above which an enhanced mass transfer is noticed (Figs 4 and 6). Equation 30 predicts that $z_{0}$ is proportional to $\Omega^{-3 / 4}$. Experimentally only a slightly higher $\phi_{\mathrm{c}}$ is observerd in Fig. 4 for the lower rotation frequencies.

In principle the gravitation effect is similar to the collision induced model of Roha [5], however instead of considering the increased viscosity by adding more particles, he calculated the increase in number of collisions of the particles above which the particles penetrate the diffusion layer and so increase the mass transfer.

Caprani et al. $[16,17]$ did not observe a critical volume-fraction in experiments with an electrolyte with higher viscosity. With addition of $60 \%$ glycerol, the viscosity, $\eta$, increases and reduces the distance, $z_{0}$ (compare with Equation 30) without particles. This reduction was so large that no critical volume fraction was observed.

\subsection{Particle size}

It can be expected that the critical volume fraction depends on the particle size. It was shown (Equation 30 ) that linear relation exists between the layer thickness, $z_{0}$, without particles and the particle size. Because a larger particle size also yields a thicker layer, $z_{0}$, a higher critical volume fraction, $\phi_{c}$, is to be expected. Figs 10-12 show that $\phi_{\mathrm{c}}$ indeed increases with particle size and that $I_{1}$ increases nearly linearly with $\phi$, with the highest increase for the largest particles. Fig. 18 presents the correlation between $\phi_{c}$ and particle size for both processes of $\mathrm{K}_{3} \mathrm{Fe}(\mathrm{CN})_{6}$ and $\mathrm{ZnO}$ reduction. For the reduction of $\mathrm{K}_{3} \mathrm{Fe}(\mathrm{CN})_{6}$, a proportional relation between critical volume fraction, $\phi_{c}$, and the particle size $a$ is found.

However, a deviation of this proportionality is observed for the reduction of $\mathrm{ZnO}$, especially for the smaller particles. A possible explanation could be the formation of zinc particles that coagulate with the $\mathrm{SiC}$ particles. The influence of the particle size on the critical rotation speed is shown in Figs 7-9. The critical rotation speed, $\Omega_{c}$, observed in these figures, is given as a function of the particles size in Fig. 19. The critical rotation speed, $\Omega_{\mathrm{c}}$, is the same for both reduction processes and is proportional to the reciprocal particle size or $\Omega_{c} \sim 1 / a$.

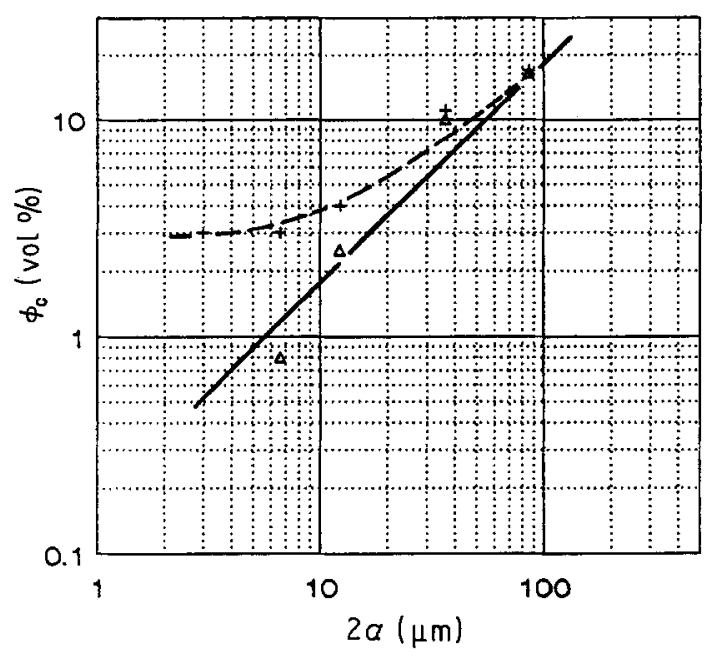

Fig. 18. The critical volume fraction $\left(\phi_{c}\right)$ as a function of the particle size (2a) for the reduction of $(\Delta) \mathrm{K}_{3} \mathrm{Fe}(\mathrm{CN})_{6}$ and $(+) \mathrm{ZnO}$.

The appearance of a critical value of the rotation speed, above which the influence of particles on mass transfer is noticeable, indicates that a certain value of the peripheral velocity $\left(v_{\mathrm{p}}\right)$ of the rotating particle is required which contributes to extra mass transfer, due to a normal electrolyte velocity component to the RDE. The rate of mass transfer $\left(v_{z}\right)$ is the result of convection and diffusion to the electrode. The particle peripheral rotation velocity $\left(v_{\mathrm{p}}\right)$ is: $v_{\mathrm{p}}=\omega_{0} a$.

This rotation speed depends on the shear rate $(\dot{\gamma})$ at a RDE [16-18] which is given by

$$
\dot{\gamma}=0.8 \Omega^{3 / 2} v^{-1 / 2} r_{\mathrm{E}}
$$

This gives, with $\omega_{0}=\frac{1}{2} \dot{\gamma}$,

$$
v_{\mathrm{p}}=0.4 \Omega^{3 / 2} v^{-1 / 2} r_{\mathrm{E}} a
$$

From the limiting current (Equations 19 and 20) the mean velocity, $v_{z}$, of the active species to the RDE can be derived

$$
v_{z}=\frac{I_{1}}{n F A c^{s}}=0.62 D^{2 / 3} v^{-1 / 6} \Omega^{1 / 2}
$$

From Equations 33 and 34 it follows

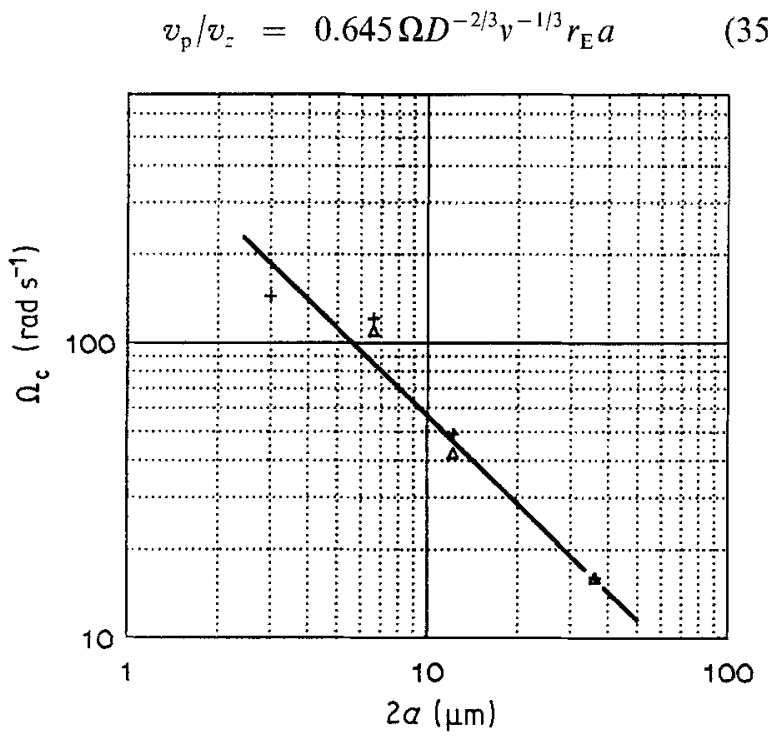

Fig. 19. The critical rotation speed $\left(\Omega_{\mathrm{c}}\right)$ as a function of the particle size (2a) for the reduction of $(\Delta) \mathrm{K}_{3} \mathrm{Fe}(\mathrm{CN})_{6}$ and $(+) \mathrm{ZnO}$ 
For the critical value, $\left(v_{\mathrm{p}} / v_{z}\right)_{\mathrm{c}} \sim \Omega_{\mathrm{c}} a$. If this critical value $\left(v_{\mathrm{p}} / v_{z}\right)_{\mathrm{c}}$ is constant: $\Omega_{\mathrm{c}} \sim 1 / a$. This was found experimentally. It follows that for small particles $\Omega_{\mathrm{c}}$ will be very high, i.e. beyond practical application. This explains why Vydra [27] did not observe an influence of very small silica particles.

\subsection{Adhesion}

Another explanation for the origin of the critical rotation speed is given by Leitel et al. [28] and Caprani et al. [16-19]. The occurrence of one or more critical values of $\Omega$ is attributed to partial blockage of the electrode surface by adhesion of particles and removal of adsorbed species at higher rotation speeds.

Careful analysis of the $\log I$ versus $\log \Omega$ plots of Caprani et al. [16-18] with $\mathrm{Al}_{2} \mathrm{O}_{3}$ suspensions shows that even three transitions in $\Omega$ are found for small particle size $(2 a \leqslant 3 \mu \mathrm{m})$. At rotation rates below the lowest transition, $\Omega_{0}$, the current of the RDE is less than the current without particles. This indicates blockage of the electrode. However, for the SiC particle size $>3 \mu \mathrm{m}$, no reduction of the limiting current is observed. As explained before, the larger particles does not reach the electrode, therefore the two transitions, $\Omega_{1}$ and $\Omega_{2}$, cannot be due to a blockage of the electrode. However, the value $\Omega_{0}$, which only appears for very small particles of $\mathrm{Al}_{2} \mathrm{O}_{3}$ suspensions $(2 a \leqslant 3 \mu \mathrm{m})$, is related with a transition to an electrode blocked by particles.

In a $\log$ - $\log$ plot of the $I_{1}$ versus $\Omega$ relation (see Fig. 20) of our results for SiC particles of $6.6 \mu \mathrm{m}$, also show only two transitions in the rotation frequencies, $\Omega_{1}$ and $\Omega_{2}$, as well as three different slopes, $p_{1}, p_{2}$ and $p_{3}$. The critical frequency, $\Omega_{c}$, in the Levich plot is somewhat greater than $\Omega_{\mathrm{L}}$. The slopes $p_{1}$ and $p_{3}$ are nearly 0.5 , according to the Levich relation. The value of $p_{2}$ varies with the volume fraction of the particles and changes from 0.5 for low fractions to 0.65 for volume fractions of $40 \%$. Therefore, some misfits exist in the Levich plots in the region of $\Omega_{c}$. The influence of the particles becomes noticeable just above $\Omega_{1}$ and increases to the rotation speed $\Omega_{2}$. Above $\Omega_{2}$, no further increase due to the particles is seen, only an increase with a slope of 0.5 according to the Levich equation. The force of adhesion between a particle and the electrode is given by Visser [29].

$$
F_{\mathrm{a}}=\frac{A_{132} a}{6 h^{2}}
$$

$A_{132}$ is the Hamaker constant between the particle (1), electrode material (2) and the electrolyte (3); $h$ is the distance between particle and electrode.

The force acting on a particle by the flow to the RDE is a corrected Stokes force [29] and is

$$
F_{\mathrm{s}}=10.2 \pi \eta a v_{\mathrm{c}}
$$

with $v_{c}=a \dot{\gamma}$

The force acting on a particle by centrifugal acceleration can be neglected at the electrode surface. Introducing the shear rate at an RDE (Equation 32),

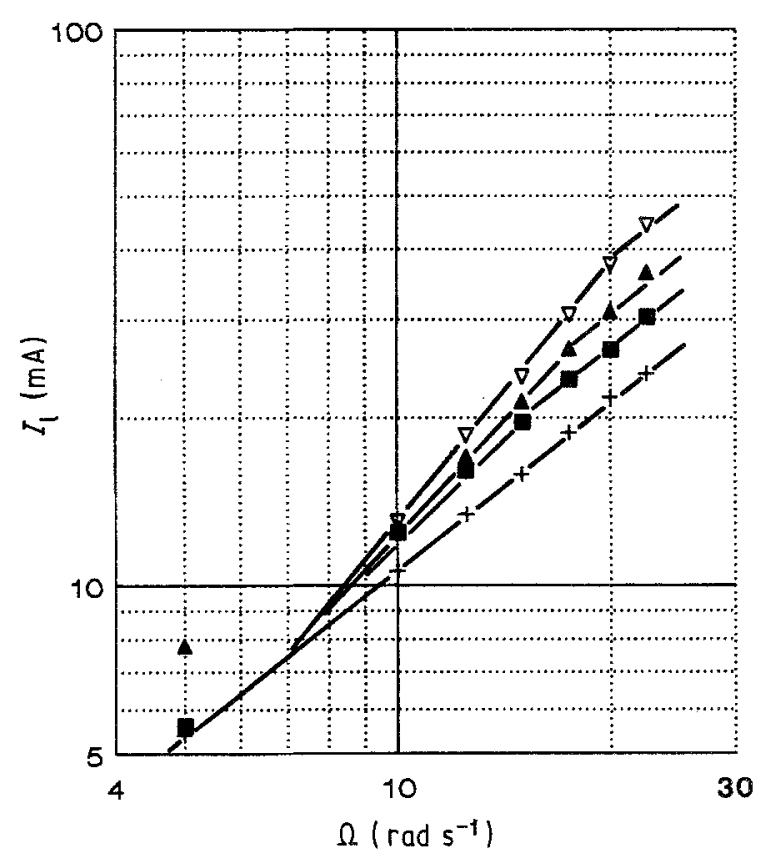

Fig. 20. In the $\log I$ against $\log \Omega$ plot for each volume fraction, two transitions and three different slopes can be seen. (Conditions as in Fig. 7.)

the force $F_{\mathrm{S}}$ is

$$
F_{\mathrm{S}}=25.6 \Omega^{3 / 2} v^{-1 / 2} r_{\mathrm{E}} a^{2} \eta
$$

At the critical frequency for the particle leaving the electrode $F_{\mathrm{S}}=F_{\mathrm{a}}$, thus

$$
\frac{A_{132}}{6 h^{2}}=25.6 \Omega^{3 / 2} v^{-1 / 2} r_{\mathrm{E}} a \eta
$$

This gives for the critical $\Omega$ value: $\Omega_{\mathrm{c}} \sim 1 / a^{2 / 3}$. This does not completely agree with the experimentallyfound relation $\Omega_{\mathrm{c}} \sim 1 / a$ (see Fig. 19). Together with the fact that no limiting currents are measured that are lower than the Levich value (as explained before), adhesion is not a possible cause.

\section{Conclusions}

The mass transfer due to the reduction of $0.05 \mathrm{M}$ $\mathrm{K}_{3} \mathrm{Fe}(\mathrm{CN})_{6}$ in $2 \mathrm{M} \mathrm{KOH}$ at the RDE is increased by the presence of suspended SiC particles. The extent of the increase depends on the volume fraction. The experimental results, expressed as $I_{1}$ versus $\Omega^{1 / 2}$ relations, shows a critical value for both the volume fraction of SiC particles, $\phi$, and the rotation speed, $\Omega$, beyond which the presence of the particles becomes effective for mass transfer. A model is developed based on a diminishing of the diffusion layer thickness due to rotation of the particles in this layer. This yields a modified Levich equation, which takes into account the volume fractions of the particles, $\phi$

$$
I_{1}=B \Omega^{1 / 2}\left[1+\left(\frac{r_{0}}{a}\right)^{3} \phi\right]
$$

It is argued that the occurrence of $\Omega_{c}$ and $\phi_{c}$ is not due to a change in hydrodynamic conditions nor a blockage of the electrode. From experiments with an 
upside-down cell, it is concluded that the appearance of $\phi_{\mathrm{c}}$ is caused by gravitational forces. The results with this cell give good agreement with the model for all volume fractions if $\Omega>\Omega_{\mathrm{c}}$.

The particle size does not play an important role except for particles larger than $\delta_{\mathrm{N}}$, where some deviation is found. The minimal approach, $z_{0}$, between particle and electrode surface can be calculated. If $z_{0} \geqslant \delta_{\mathrm{N}}$, the particles cannot affect the mass transfer to the electrode. It is further concluded that the peripheral velocity of the rotating particles must exceed a critical value in order to contribute to enhanced mass transfer. It can be shown that a critical rotation rate $\Omega_{\mathrm{c}}$ must exist that is proportional to $1 / a$. This was confirmed experimentally.

\section{Acknowledgements}

We gratefully thank Professor A. K. Chesters for his valuable suggestions and comments. The present investigations were carried out with support of the Netherlands Organisation for the Advancement of Pure Research (S.T.W.).

\section{References}

[1] A. Storck and D. Hutin, Electrochim. Acta 26 (1981) 127.

[2] N. Ib1, Chemie-Ing. Tech. 43 (1971) 202.

[3] O. N. Cavatorta and U. Böhm, J. Appl. Electrochem. 17 (1987) 340 .

[4] E. Leitel, A. Pinkowski and K. P. Thiessen, Z. Phys. Chem. (Leipzig) 260 (1979) 448.

[5] D. J. Roha, M. S. Thesis, University of California, Berkeley (1981).

[6] J. W. Smith and D. H. King, Can. J. Chem. Eng. 53 (1975) 41.
[7] J. Postlethwaith and D. N. Holdner, Can. J. Chem. Eng. 53 (1975) 31.

[8] Idem, ibid. 54 (1976) 225

[9] E. Heitz, in Extended Abstracts of the 27th Meeting of ISE, Zurich (1976) 17.

[10] H. Zeilmaker and E. Barendrecht, in Extended Abstracts of the 31st Meeting of ISE, Venice, Italy (1980) p. 911.

[11] G. C. Pini and P. L. Deanna, Electrochim. Acta 22 (1977) 1423.

[12] K. H. Keller, Fed. Proc. 30 (1971) 1591.

[13] G. Antonini, G. Guiffint and D. Quemada, J. Chim. Phys. France 71, (1971) 1123.

[14] G. Antonini, G. Guiffint, D. Quemada and A. M. Dosne, Biorheology 15 (1978) 111.

[15] W. A. Hyman, Trans. of the ASME 56 (1975) 58.

[16] A. Caprani, A. Ambari, C. Desluis, B. Tribollet, M. M. de Ficquelmont-Loizos and M. Nackacke, in Proceedings of the 9th International Congress on Rheology, Mexico, Vol. 4 (1981) p. 1.

[17] A. Caprani, M. M. de Ficquelmont-Loizos and M. Nackacke, Physico Chemical Hydrodynamics 6 (1985) 567.

[18] M. M. de Ficquelmont-Loizos, L. Tamisier and A. Caprani, J. Electrochem. Soc. 135 (1988) 626.

[19] A. Caprani, M. M. de Ficquelmont-Loizos, L. Tamisier and P. Peronneau, ibid. 135 (1988) 634.

[20] C. Deslouis, A. Ezzidi and B. Tribollet, Physico Chemical Hydrodynamics 9 (1987) 63.

[21] Yu. V. Pleskov and V. Yu. Filinivskii, 'The rotating disc electrode', Consultants Bureau, New York and London (1967) p. 11.

[22] P. J. Sonneveld, W. Visscher and E. Barendrecht, in Extended Abstracts of the 38th Meeting of the ISE, Maastricht, Vol. 1. (1987) p. 225.

[23] H. Brenner, in 'Progress in heat mass transfer', Vol. 6, (edited by G. Hetstoni, S. Sideman and J. P. Hartnelt) Pergamon Press, New York (1972) p. 509.

[24] G. K. Batchelor, 'An introduction to fluid dynamics', Cambridge University Press (1970) p. 248.

[25] G. I. Batchelor and J. T. Green, J. Fluid Mech. 56 (1972) 375.

[26] E. Barnea and J. Mizraki, Chem. Eng. J. 5 (1973) 171.

[27] F. Vydra, J. Electroanal. Chem. 25 (1970) Appendix 13.

[28] E. Leitel, A. Pinkowski and K. P. Thiessen, Z. Phys. Chem. (Leipzig) 260 (1979) 448.

[29] J. Visser, Rept. Progr. Appl. Chem. 53 (1968) 714. 